Chapman University

Chapman University Digital Commons

Sociology Faculty Articles and Research

Sociology

$1-10-2017$

\title{
Smoking Selectivity Among Mexican Immigrants to the United States Using Binational Data, 1999-2012
}

Nancy L. Fleischer

University of Michigan

Annie Ro

University of California, Irvine

Georgiana Bostean

Chapman University, gbostean@chapman.edu

Follow this and additional works at: http://digitalcommons.chapman.edu/sociology_articles

Part of the Chicana/o Studies Commons, Community-Based Research Commons, Ethnic Studies Commons, Latina/o Studies Commons, Medicine and Health Commons, Other Medicine and Health Sciences Commons, Other Sociology Commons, Place and Environment Commons, $\underline{\text { Race and Ethnicity Commons, Social Statistics Commons, and the Substance Abuse and Addiction }}$ Commons

\section{Recommended Citation}

Fleischer, N.L, Ro, A., \& Bostean, G. (2017). Smoking selectivity among Mexican immigrants to the United States using binational data, 1999-2012. Preventative Medicine, 97: 26-32. doi: 10.1016/j.ypmed.2017.01.004

This Article is brought to you for free and open access by the Sociology at Chapman University Digital Commons. It has been accepted for inclusion in Sociology Faculty Articles and Research by an authorized administrator of Chapman University Digital Commons. For more information, please contact laughtin@chapman.edu. 


\section{Smoking Selectivity Among Mexican Immigrants to the United States Using Binational Data, 1999-2012}

\section{Comments}

NOTICE: this is the author's version of a work that was accepted for publication in Preventative Medicine. Changes resulting from the publishing process, such as peer review, editing, corrections, structural formatting, and other quality control mechanisms may not be reflected in this document. Changes may have been made to this work since it was submitted for publication. A definitive version was subsequently published in Preventative Medicine, volume 97, in 2017. DOI: 10.1016/j.ypmed.2017.01.004

The Creative Commons license below applies only to this version of the article.

\section{Creative Commons License}

\section{(c) 1 (1) 90}

This work is licensed under a Creative Commons Attribution-Noncommercial-No Derivative Works 4.0 License.

\section{Copyright}

Elsevier 


\section{Accepted Manuscript}

Smoking selectivity among Mexican immigrants to the United States using binational data, 1999-2012

Nancy L. Fleischer, Annie Ro, Georgiana Bostean

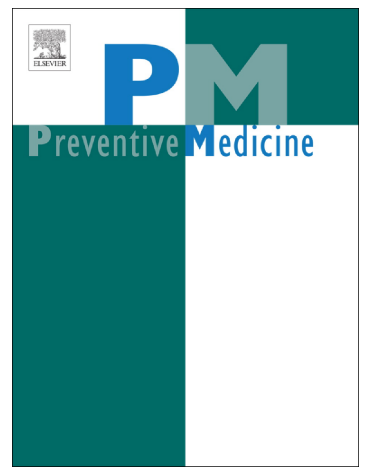

PII:

S0091-7435(17)30004-X

DOI: doi: 10.1016/j.ypmed.2017.01.004

Reference: YPMED 4910

To appear in: Preventive Medicine

Received date:

30 June 2016

Revised date:

23 November 2016

Accepted date:

9 January 2017

Please cite this article as: Nancy L. Fleischer, Annie Ro, Georgiana Bostean, Smoking selectivity among Mexican immigrants to the United States using binational data, 1999-2012. The address for the corresponding author was captured as affiliation for all authors. Please check if appropriate. Ypmed(2017), doi: 10.1016/j.ypmed.2017.01.004

This is a PDF file of an unedited manuscript that has been accepted for publication. As a service to our customers we are providing this early version of the manuscript. The manuscript will undergo copyediting, typesetting, and review of the resulting proof before it is published in its final form. Please note that during the production process errors may be discovered which could affect the content, and all legal disclaimers that apply to the journal pertain. 
Title: Smoking selectivity among Mexican immigrants to the United States using binational data, 1999-2012

\section{Authors:}

Nancy L. Fleischer, ${ }^{a}$ Annie Ro, ${ }^{b}$ Georgiana Bostean ${ }^{c}$

${ }^{a}$ Center for Social Epidemiology and Population Health, Department of Epidemiology, School of Public Health, University of Michigan, 1415 Washington Heights, Ann Arbor, MI 48109, USA ${ }^{b}$ Program in Public Health, UC Irvine, 653 E. Peltason Road, Irvine, CA 92697, USA ${ }^{\mathrm{c} S}$ Sociology Department and Environmental Science \& Policy Program, Chapman University, One University Drive, Orange, CA 92866, USA

\section{Corresponding Author:}

Nancy L. Fleischer

Email: nancyfl@umich.edu

Abstract word count: 246

Main text word count: 3815 


\begin{abstract}
Mexican immigrants have lower smoking rates than US-born Mexicans, which some scholars attribute to health selection - that individuals who migrate are healthier and have better health behaviors than their non-migrant counterparts. Few studies have examined smoking selectivity using binational data and none have assessed whether selectivity remains constant over time. This study combined binational data from the US and Mexico to examine: 1) the extent to which recent Mexican immigrants (<10 years) in the US are selected with regard to cigarette smoking compared to non-migrants in Mexico, and 2) whether smoking selectivity varied between 2000 and 2012 - a period of declining tobacco use in Mexico and the US. We combined repeated cross-sectional US data $(\mathrm{n}=10,901)$ on adult (ages 20-64) Mexican immigrants and US-born Mexicans from the 1999/2000 and 2011/2012 National Health Interview Survey, and repeated cross-sectional Mexican data on non-migrants $(n=67,188)$ from the 2000 Encuesta Nacional de Salud and 2012 Encuesta Nacional de Salud y Nutrición. Multinomial logistic regressions, stratified by gender, predicted smoking status (current, former, never) by migration status. At both time points, we found lower overall smoking prevalence among recent US immigrants compared to non-migrants for both genders. Moreover, from the regression analyses, smoking selectivity remained constant between 2000 and 2012 among men, but increased among women. These findings suggest that Mexican immigrants are indeed selected on smoking compared to their non-migrating counterparts, but that selectivity is subject to smoking conditions in the sending countries and may not remain constant over time.
\end{abstract}

Keywords: smoking, health selection, immigrants, Mexico, United States 


\section{INTRODUCTION}

Latinos in the United States, particularly immigrants, have lower mortality rates and better health outcomes than more socioeconomically advantaged groups - a finding called the "Hispanic Paradox" (Markides and Coreil, 1986). Evidence for the paradox has been strongest among Mexican immigrants (Palloni and Arias, 2004), who comprise the majority of Latino immigrants to the US (Stepler and Brown, 2015). Recent research suggests that the lower smoking prevalence among Mexican immigrants compared to other groups may account for this mortality advantage (Fenelon, 2013). A major explanation for these smoking behaviors is the health selection hypothesis, which posits that individuals who migrate are healthier and have better health behaviors compared to those who do not migrate (Riosmena et al., 2013). Health selection is most accurately tested using binational data to compare recent immigrants to nonmigrants in the origin country. However, most research on health selection has only been able to measure selection indirectly using US-based data; differences between immigrants and the USborn are usually attributed to health selection. A small number of binational studies have examined health selection in outcomes such as obesity, disability, other physical health measures, and self-rated health (Angel et al., 2008; Bostean, 2013; Ro and Fleischer, 2014; Rubalcava et al., 2008), but binational work on smoking is limited (Sudhinaraset, 2015).

The few studies examining smoking have found mixed evidence of selectivity. One study found no differences in current smoking between Mexican immigrants to the US and their nonmigrating counterparts in Mexico; this study used Mexico data from 2001 and US data from 1997-2007 (Riosmena et al., 2013). Another found lower smoking prevalence among Mexican immigrants than among Mexicans, using Mexico data from 2002-2003 and US data from 20062007 (Bosdriesz et al., 2013). However, research to date has not considered how changes in the 
sending country tobacco control environment may affect smoking selectivity over time. This is a potentially significant oversight for smoking and Mexican immigrants in particular, as there have been several important tobacco control policy changes in Mexico within the last decade. In 2004, Mexico ratified the Framework Convention on Tobacco Control, and in 2008 the Mexican legislature passed the General Tobacco Control Law, which catalyzed several tobacco control policies, including higher taxes, stronger health warning labels, and smoke-free policies (Ramírez-Barba et al., 2008). Overall smoking prevalence in Mexico declined from $28 \%$ in the late 1990s (Tapia-Conyer et al., 2001) to 22\% in 2011 (2012a). During this same period, there was also a decrease in smoking in the US, including among Mexicans in the US: current smoking prevalence among Mexicans in the US decreased from 25\% to $17 \%$ for men and from $13 \%$ to $9 \%$ for women between the periods 1992-1996 and 2003-2007 (Blanco et al., 2014).

In the context of tobacco control and subsequent smoking declines in Mexico, it is unclear whether smoking selectivity among Mexican immigrants to the US has remained constant. If the decline in smoking in Mexico is reflected among recent immigrants in the US, there are three possible scenarios. In the first, smoking selectivity may decrease as the heterogeneity between immigrants and non-migrants diminishes. In other words, there is less variation in smoking prevalence in Mexico overall, truncating differences between immigrants and non-migrants. This could occur as a result of restrictive smoking policies that reduce smoking among non-migrants to a greater extent. For instance, urban residents are more likely to smoke, but less likely to migrate. If smoking restrictions, such as smoke-free air laws, had a greater effect on urban-dwelling, non-migrants' smoking behaviors, this would decrease the smoking difference, and therefore smoking selectivity, between migrants and non-migrants. In the second scenario, there may be no change in smoking selectivity if the reduction in smoking 
prevalence is similar in magnitude for immigrants and non-migrants. Finally, smoking selectivity may increase if the decline in smoking prevalence is concentrated among immigrants and not their non-migrating counterparts. This could happen if individuals who think they may migrate practice better health behaviors (e.g., do not smoke) in anticipation of future opportunities (Kennedy et al., 2006). To test these potential dynamics in smoking selectivity, multiple time points of binational data from the US and Mexico are needed.

Migrants are also selected in terms of socio-demographic characteristics including gender, age, education, employment, and place of residence within Mexico (Van Hook et al., 2012). To account for these differences, we must estimate individuals' likelihood of migrating. Thus, an ideal test of smoking selectivity compares recent immigrants in the receiving country to non-migrants in the sending country by their migration likelihood. If selectivity in smoking exists, we would expect the smallest difference in smoking prevalence to be between recent US immigrants and non-migrants with high migration likelihood, and the largest differences to be between recent US immigrants and non-migrants with low migration likelihood. There may also be a gradient among non-migrating individuals, such that those with the highest migration likelihood will have the lowest smoking prevalence and those with the lowest migration likelihood will have the highest.

Finally, the processes driving both smoking and migration are gendered. Mexican women have much lower smoking prevalence than men (Christopoulou et al., 2013; Jamal et al., 2014). The factors influencing smoking behaviors also differ by gender, with age and educational gradients in smoking differing for men and women (Christopoulou et al., 2013). Furthermore, women are more likely to migrate to follow a spouse, whereas men are most likely to migrate for employment, which suggests that the migration selection mechanisms differ for men and women 
(Cerrutti and Massey, 2001; Massey et al., 2006). Therefore, smoking selectivity patterns should be examined separately for men and women.

This study examines: 1) the extent to which Mexican immigrants to the US are selected with regard to cigarette smoking, and 2) whether smoking selectivity varies between 2000 and 2012. Addressing the first question, we hypothesize that: (a) recent Mexican immigrants in the US will have lower smoking prevalence than Mexican nationals, and (b) the greatest difference will be between recent immigrants and non-migrants with lowest migration likelihood. Addressing the second question, we test three competing hypotheses about changes in smoking selectivity between 2000 and 2012: greater smoking selectivity, less selectivity, or no change in selectivity. Finally, due to the gendered patterns of smoking and migration, we expect differences between men and women in these patterns over time.

\section{METHODS}

\section{Data sources}

We constructed a binational data set from the 1999/2000 and 2011/2012 waves of the US National Health Interview Survey (NHIS) (NCHS, 2012), the 2000 Mexican National Health Survey (ENSA) (Olaiz et al., 2003; Valdespino et al., 2003), and the 2012 Mexican National Health and Nutrition Survey (ENSANUT) (Gutierrez et al., 2012). The years were chosen based on availability of the Mexican surveys for the time periods before and after implementation of the tobacco control policies. In order to ensure adequate sample size for Mexican immigrants, we combined data from two waves of NHIS to correspond with the Mexican datasets. All surveys were nationally representative, cross-sectional, household surveys conducted in their respective countries. All NHIS data were downloaded from the Integrated Health Interview Series (IHIS) (2012b). 
Adults aged 20 to 64 years with data on smoking status and relevant covariates were included in the sample. From NHIS, we included all respondents who self-identified as Mexican or Mexican-American. Our final sample size was 5,020 for 1999/2000 NHIS; 5,881 for 2011/2012 NHIS; 37,447 for 2000 ENSA; and 29,741 for 2012 ENSANUT. We dropped 346 cases (251 from 1999/2000 NHIS, 95 from 2011/2012 NHIS) with missing information on covariates.

\section{Variables}

Smoking status. Smoking was coded into three categories: current, former, and never smokers. A current smoker was classified according to whether a person had smoked at least 100 cigarettes in his/her lifetime and was currently smoking; a former smoker had smoked at least 100 cigarettes in his/her lifetime but was not currently smoking; and a never smoker had never smoked or smoked fewer than 100 cigarettes in his/her lifetime (CDC, 2015).

Migration status. Mexicans in the US (from NHIS) were classified as recent immigrants if they immigrated to the US from Mexico in the past 9 years. We also included additional comparison groups of longer-term Mexican immigrants (have resided in US for 10 or more years), and US-born Mexicans. Mexican nationals (from Mexico ENSA and ENSANUT) were classified as having low, medium, or high likelihood of migrating to the US. Because we could not directly assess whether respondents had ever migrated to the US in the ENSA or ENSANUT, we estimated migration likelihood for Mexican nationals using data from the 2000 and 2010 Mexican Censuses, downloaded from the Integrated Public Use Microdata Series International (2014). We coded whether someone in the household had gone to live in the US in the past five years as our marker of household migration, which has been used to approximate migration likelihood in previous studies (Buttenheim et al., 2010; Ro and Fleischer, 2014). In each 
Mexican Census dataset, we regressed household migration on age, age squared, gender, marital status, education, employment, state-level indicator variables, municipio-level migration rate, and urbanicity due to their relevance to Mexico-US migration (Massey and Espinosa, 1997; Van Hook et al., 2012). We used a logistic regression model with robust standard errors, and from this, we predicted the log-odds of migration for respondents in ENSA and ENSANUT. We created a variable indicating low, medium, and high predicted migration likelihood based on tertiles from the census data within the weighted samples of ENSA and ENSANUT.

Covariates. All regression models adjusted for age, education (less than primary, primary, secondary, university completed), marital status (married/cohabiting vs. unmarried), and employment status (currently employed vs. not employed).

\section{Statistical analysis}

We first combined the US 1999/2000 NHIS data with 2000 ENSA, and 2011/2012 NHIS data with 2012 ENSANUT and examined binational differences within each period. We then combined all datasets to conduct a series of multinomial logistic regression models for smoking status to compare periods. We calculated odds ratios incorporating person weights for each dataset (adjusting for combined NHIS waves by dividing weights by number of years combined) and accounted for clustering with robust standard errors. All models were stratified by gender. Analyses were conducted in Stata 14.

Our analyses test our two main hypotheses: (1) that there is positive selectivity in smoking, with recent immigrants having lower odds of smoking than non-migrants (Models 1 and 2), and (2) that smoking selectivity differs between the two time points (Models 3 and 4). Model 1 examined smoking selectivity for current and former versus never smoking in 2000, using recent Mexican immigrants in the US as the comparison group. Model 2 repeated the 
analysis for 2012. Model 3 combined all years with an indicator variable for the period (2012 versus 2000). Finally, Model 4 added an interaction between migration status and period to test for changes in smoking selectivity between the two time points. We conducted an F-test with five degrees of freedom to test the significance of the joint interaction in the final model. We also graphed predicted probabilities for smoking status by period to display the interaction.

To test hypothesis 2 regarding changes in smoking selectivity over time, we conducted a Wald test comparing 2000 and 2012, contrasting the difference between people in the low migration likelihood category and those in the recent immigrant category using Model 3.

\section{RESULTS}

Table 1 provides sociodemographic characteristics for people residing in the US and Mexico at two time points (Table 1). Among men, Mexican nationals and US Mexicans were similar in age, marital status, and employment, but Mexican national men had lower education at both time periods. Among women, age, education, and marital status followed similar patterns to the men. Mexican national women had much lower prevalence of employment than US Mexican women at both time points.

Current smoking prevalence decreased between 2000 and 2012 in Mexico and the US, for men and women, with variation by migration status (Table 2). At both time points, recent immigrants to the US had lower smoking prevalence than all Mexican nationals, indicating some smoking selectivity. For men, the greatest difference was between recent immigrants and those with the lowest migration likelihood (36.8\% versus $20.2 \%$ in 2000 and $33.8 \%$ versus $19.1 \%$ in 2012). For women, the difference between recent immigrant women and Mexican national women with a low migration likelihood grew between 2000 and 2012 (12.4\% versus 9.4\% in 2000 and $13.7 \%$ versus $4.3 \%$ in 2012 ). 
Regression analyses combining the Mexico and US data confirmed the bivariate differences (Table 3). Since the patterns for current and former versus never smoking were very similar, we focus on the results for current smoking. Selectivity in current smoking was apparent among men in both 2000 and 2012. When compared to recent Mexican immigrants, Mexican national men had higher odds of being current versus never smokers at both time periods. For example, in 2000, the OR for Mexican nationals with low migration likelihood was 2.93 (Model 1, 95\% CI: 2.16, 3.98), medium migration likelihood was 2.98 (95\% CI: 2.18, 4.08), and high migration likelihood was 3.31 (95\% CI: 2.31, 4.24). We expected the largest differences to be for Mexican nationals with the lowest migration likelihood, but the ORs for all three groups were similar. In 2012, however, there was a slight gradient among the Mexican national men such that those with low migration likelihood had the highest OR and those with the highest likelihood had the lowest. Model 3 confirmed lower current smoking prevalence in 2012 versus 2000 for all groups $(\mathrm{OR}=0.76,95 \% \mathrm{CI}: 0.70-0.83)$.

Smoking selectivity did not appear to change greatly over the two time points for men. The difference in the probability for current smoking from Model 3 between Mexican national men with low migration likelihood and Mexican recent immigrant men was $17.9 \%$ in 2000 and $16.2 \%$ in 2012 . The magnitude of this difference is $1.7 \%$, which was not significantly significant (Wald Test, $P=0.69$ ). Although the test of interaction in Model 4 indicated differences across time in the relationship between migration status and smoking status $(P=0.0091)$, this was likely due to the clearer gradient among Mexican nationals by migration likelihood in 2012 . Figure 1a displays predicted probabilities from Model 4 and shows a clearer downward gradient among Mexican non-migrants in 2012 compared to 2000. Graphs for former and never smoking can be found in the Supplementary Material. 
Among women, there was no evidence of smoking selectivity in 2000, as there were no statistically significant differences in the odds of being a current versus never smoker when comparing Mexican national women to recent Mexican immigrant women in the US (Model 1, Table 3). However, differences emerged by 2012, and it appears that smoking selectivity increased. Compared to recent immigrants, Mexican national women with low and medium migration likelihood had a higher odds of being current versus never smokers (Model 2: OR 3.65, 95\% CI: 1.79, 7.44 for low; OR $3.3395 \%$ CI 1.56, 6.73 for medium). The ORs followed a gradient among Mexican nationals and there was no statistically significant difference for Mexican national women with a high migration likelihood compared to recent US immigrants. The difference in predicted probabilities between Mexican national women with low migration likelihood and recent immigrants was $2.6 \%$ in 2000 and $9.0 \%$ in 2012 , a statistically significant increase (Wald test, $P=0.033$ ). Model 3 confirmed lower smoking in 2012 versus 2000 for all groups $(\mathrm{OR}=0.80,95 \% \mathrm{CI}: 0.72-0.88)$.

Changes in smoking selectivity were observed among women (Model 4). We confirmed differences across time in the relationship between migration status and smoking status in the interaction model $(P=0.0026)$. Specifically, there were no differences in current smoking probability between recent immigrants and any of the Mexican national groups in 2000 (Figure 1b). By 2012, Mexican national women with a lower migration likelihood had a higher probability of current smoking than recent immigrants. Former smoking had similar patterns to current smoking among women.

Although not a central focus of this study, it is worth noting that there were no significant differences in current smoking between recent and long-term immigrants at either time point, for men or women. 


\section{DISCUSSION}

This study used binational data to examine smoking selectivity, and changes in smoking selectivity over time, among Mexican immigrants in the US relative to non-migrants in Mexico. We found support for the hypothesis that recent immigrants have lower smoking prevalence than their non-migrant counterparts, particularly among men. We found partial support for a gradient among non-migrants, with the greatest difference being between recent immigrants and nonmigrants with lowest migration likelihood. In terms of changes in smoking selectivity, we found increased selectivity only among women.

Our findings are largely consistent with our first hypothesis, that recent Mexican immigrants in the US are positively selected on smoking behaviors, with lower odds of current smoking than Mexican nationals who are not likely to migrate. In both 2000 and 2012, Mexican national men who were least likely to migrate had a higher odds of being a current smoker than recent immigrant men. For women, however, there was no evidence of smoking selectivity in 2000, although we did see it emerging in 2012. Our findings stand in contrast to one of the few prior studies to examine smoking selectivity among Mexicans using binational data (Riosmena et al., 2013), which did not find significant differences between immigrants and non-migrants; however, they examined older adult males and did not examine migration likelihood. Our results suggest that smoking selectivity may be more pronounced at working ages.

This brings us to our second research question regarding a change in smoking selectivity over time. For men, we found that although smoking prevalence decreased between years, smoking selectivity remained constant between the two time points, providing support for the second scenario we described in the Introduction. In contrast, women displayed increased 
selectivity in smoking between migrants and non-migrants in 2012 compared to 2000, corresponding to the first scenario we described. These results mirror those from a study of obesity that found that differences in obesity between migrants and non-migrants grew over time (Ro and Fleischer, 2014). Collectively, our results suggest that the health differential between migrants and their non-migrating counterparts is not static and corresponds with broader health shifts in both the sending and receiving countries, and that gendered processes shape these associations.

It may be that the more restrictive tobacco control environment in Mexico differentially affects Mexican women such that those with high migration likelihood are most likely to experience a decline in smoking. One potential explanation for this finding is unmeasured confounding by characteristics that underlie smoking behavior and migration likelihood (e.g., education); however, we posit this is not the case. First, we accounted for such differences in our migration likelihood estimation. Second, socioeconomic status is only one of many sociodemographic characteristics in our migration likelihood estimation. Other factors, such as urbanicity, would suggest the opposite patterns for smoking, as smoking is higher among urban Mexicans but migration is lower (Van Hook et al., 2012). It is possible, though, that there are latent constructs that underlie both migration and smoking. For example, Kennedy and colleagues (2006) suggest that individuals who expect to migrate avoid unhealthy behaviors in order to maximize their future life experiences. Restrictive smoking policies may increase health selection among those who are most likely to migrate, by reinforcing these behaviors via social context.

There are likely additional forces at play that contribute to the widening difference between recent immigrant and non-migrant women between 2000 and 2012. First, our recent 
immigrant group includes immigrants who have lived in the US up to 10 years and it is plausible that immigrants' smoking behaviors adjusted to the increasing US tobacco control environment by 2012. In other words, recent immigrants in 2012 may not have had lower smoking prevalence at the point of entry compared to those in 2000, but their smoking may have declined after living in an increasingly controlled US tobacco environment for up to 10 years.

Why did smoking selectivity increase among women but not men? First, the overall smoking patterns between men and women are very different. In Mexico, men smoke substantially more and smoking policies may have spurred an overall drop. For women, there was little change in overall prevalence between the two time points, but their lower smoking may be more sensitive to nuances by migration likelihood. Second, women lag in stages of the smoking transition; as countries develop, men have an earlier uptake of smoking and subsequent reduction (Lopez et al., 1994). It is possible that men experienced a shift in smoking selectivity earlier than our study time frame. Finally, there may be compositional differences among women at our two time points. For example, Mexican women's education and employment increased while men's stayed the same at the two time points. The differences between female migrants and non-migrants may then actually be reflecting a cohort effect that is intertwined with the changing smoking landscape in Mexico.

Due to sample size limitations and the low prevalence of current smoking among women, we were unable to examine recent immigrants within 5 years of migration, rather than within 10 years. Although not central to this study, we found no difference between recent and long-term immigrants; future research should examine differences among immigrants by duration of residence, also accounting for taking potential cohort effects arising from changes in sending country context. A potential limitation of this study is the differing survey collection methods of 
the US and Mexico data. The NHIS data were collected through phone interview, while the Mexico data were collected through in-person interview. However, the key variables, smoking and migration status, were self-reported in both datasets. Although there may be response bias (because of social desirability) in self-reported smoking among the Mexico respondents because of the in-person format. However, if this impacted our results, it would likely to bias the results in a conservative direction. We found that women in Mexico reported higher smoking prevalence than migrant women; therefore, if there is underreporting of smoking among Mexican women, our selectivity findings would be strengthened. Finally, our migration likelihood measure, estimated from the Mexican Census, focuses on household migration; nevertheless, this is a reasonable measure when compared to alternatives such as area migration (Buttenheim et al., 2010; Ro and Fleischer, 2014).

\section{Conclusions}

Overall, findings provide support for selectivity in smoking behaviors among Mexican immigrants to the US, but limited support for the notion that the changing tobacco control environment in Mexico has weakened smoking selectivity. Although our findings may be unique to the US-Mexico case, changes in the tobacco environment in immigrants' origin countries do affect the smoking patterns immigrants bring to the US. More binational studies are needed to illuminate the role of sending country contextual changes in shaping health selection and in contributing to the Hispanic Paradox. This also suggests that monitoring changes in tobacco prevalence in sending country trends might improve our understanding of, and ability to anticipate, smoking trends among newly arrived cohorts of immigrants. This is particularly relevant within the context of rapidly changing tobacco control environments globally. This information may help to identify more precisely at-risk groups of immigrants for smoking 
prevention and cessation interventions and provides the evidence base for more nuanced priority setting in binational tobacco control efforts. 


\section{Funding}

This research did not receive any specific grant from funding agencies in the public, commercial, or not-for-profit sectors.

\section{Declaration of Interests}

No conflicts of interest. 


\section{References}

2012a. Encuesta Nacional de Adicciones 2011: Reporte de Tabaco. Instituto Nacional de Psiquiatria Ramon de la Fuente Muniz (INPRFM)/Secretaria de Salud, Mexico.

2012b. Minnesota Population Center and State Health Access Data Assistance Center. Integrated Health Interview Series: Version 5.0. University of Minnesota, Minneapolis.

2014. Minnesota Population Center. Integrated Public Use Microdata Series, International: Version 6.3 [Machine-readable Database]. University of Minnesota, Minneapolis.

Angel, R.J., Angel, J.L., Hill, T.D., 2008. A comparison of the health of older Hispanics in the United States and Mexico - Methodological challenges. J Aging Health 20:3-31.

Blanco, L., Garcia, R., Perez-Stable, E.J., White, M.M., Messer, K., Pierce, J.P., Trinidad, D.R., 2014. National trends in smoking behaviors among Mexican, Puerto Rican, and Cuban men and women in the United States. Am J Public Health 104:896-903.

Bosdriesz, J.R., Lichthart, N., Witvliet, M.I., Busschers, W.B., Stronks, K., Kunst, A.E., 2013. Smoking Prevalence among Migrants in the US Compared to the US-Born and the Population in Countries of Origin. Plos One 8.

Bostean, G., 2013. Does Selective Migration Explain the Hispanic Paradox? A Comparative Analysis of Mexicans in the US and Mexico. J Immigr Minor Healt 15:624-35.

Buttenheim, A., Goldman, N., Pebley, A.R., Wong, R., Chung, C., 2010. Do Mexican immigrants "import" social gradients in health to the US? Soc. Sci. Med. 71:1268-76.

CDC, 2015. National Health Interview Survey Adult Tobacco Use Information Glossary. Centers for Disease Control and Prevention, Atlanta, GA.

Cerrutti, M., Massey, D.S., 2001. On the auspices of female migration from Mexico to the United States. Demography 38:187-200.

Christopoulou, R., Lillard, D.R., de la Miyar, J.R.B., 2013. Smoking behavior of Mexicans: patterns by birth-cohort, gender, and education. Int J Public Health 58:335-43.

Fenelon, A., 2013. Revisiting the Hispanic mortality advantage in the United States: The role of smoking. Social science \& medicine 82:1-9.

Gutierrez, J., Rivera-Dommarco, J., Shamah-Levy, T., Villalpando-Hernandez, S., Franco, A., CuevasNasu, L., Romero-Martinez, M., Hernandez-Avila, M., 2012. Encuesta Nacional de Salud y Nutricion 2012. Resultados Nacionales. Instituto Nacional de Salud Publica (MX), Cuernavaca, Mexico.

Jamal, A., Agaku, I.T., O'Connor, E., King, B.A., Kenemer, J.B., Neff, L., 2014. Current Cigarette Smoking Among Adults - United States, 2005-2013. Mmwr-Morbid Mortal W 63:1108-12.

Kennedy, S., McDonald, J.T., Biddle, N., 2006. The healthy immigrant effect and immigrant selection: evidence from four countries. SEDAP Research Paper No. 164. 
Lopez, A.D., Collishaw, N.E., Piha, T., 1994. A descriptive model of the cigarette epidemic in developed countries. Tob Control 3:242-47.

Markides, K.S., Coreil, J., 1986. The Health of Hispanics in the Southwestern United-States - an Epidemiologic Paradox. Public Health Rep 101:253-65.

Massey, D.S., Espinosa, K.E., 1997. What's Driving Mexico-U.S. Migration? A Theoretical, Empirical, and Policy Analysis. American Journal of Sociology 102:939-99.

Massey, D.S., Fischer, M.J., Capoferro, C., 2006. International migration and gender in Latin America: A comparative analysis. Int Migr 44:63-91.

NCHS, 2012. About the National Health Interview Survey. Center for Disease Control and Prevention, Washington, DC.

Olaiz, G., Rojas, R., Barquera, S., Shamah, T., Aguilar, C., Cravioto, P., López, P., Hernández, M., Tapia, R., et al., 2003. Encuesta Nacional de Salud 2000. Tomo I. Vivienda, población y utilización de servicios de salud. Instituto Nacional de Salud Pública, Cuernavaca, Morelos, México.

Palloni, A., Arias, E., 2004. Paradox lost: Explaining the Hispanic adult mortality advantage. Demography 41:385-415.

Ramírez-Barba, É.J., Saro-Boardman, E., Vázquez-Guerrero, A., Vázquez-Guerrero, M.Á., 2008. Ley General para el Control del Tabaco en México. Salud Publica de Mexico 50:372-83.

Riosmena, F., Wong, R., Palloni, A., 2013. Migration Selection, Protection, and Acculturation in Health: A Binational Perspective on Older Adults. Demography 50:1039-64.

Ro, A., Fleischer, N., 2014. Changes in health selection of obesity among Mexican immigrants: A binational examination. Social science \& medicine 123:114-24.

Rubalcava, L.N., Teruel, G.M., Thomas, D., Goldman, N., 2008. The healthy migrant effect: New findings from the Mexican family life survey. Am J Public Health 98:78-84.

Stepler, R., Brown, A., 2015. Statistical Portrait of Hispanics in the United States, 1980 - 2013. Pew Research Center, Washington, DC.

Sudhinaraset, M., 2015. Review of Binational Study Designs for Migration and Health Research: USMexico Studies and Considerations for Future Research, The Cross-Border Connection: Immigrants, Emigrants, and their Homelands. UCLA International Institute, Los Angeles, CA.

Tapia-Conyer, R., Kuri-Morales, P., Hoy-Gutierrez, M.J., 2001. [Epidemiologic overview of smoking in Mexico]. Salud Publica Mex 43:478-84.

Valdespino, J., Olaiz, G., López-Barajas, M., Mendoza, L., Palma, O., Velázquez, O., Tapia, R., Sepúlveda, J., 2003. Encuesta Nacional de Salud 2000. Tomo I. Vivienda, población y utilización de servicios de salud. Instituto Nacional de Salud Pública, Cuernavaca, Morelos, México.

Van Hook, J., Baker, E., Altman, C.E., Frisco, M.L., 2012. Canaries in a coalmine: Immigration and overweight among Mexican-origin children in the US and Mexico. Soc. Sci. Med. 74:125-34. 


\section{Figure Legends}

Figure 1. Predicted Probability of Current Smoking Among Men and Women According to Migration Status, Mexico and United States, 1999-2012 
Table 1. Selected Characteristics of Study Sample, Mexico and United States, 1999-2012

\begin{tabular}{|c|c|c|c|c|c|c|c|c|}
\hline & \multicolumn{4}{|c|}{ 1999-2000 } & \multicolumn{4}{|c|}{ 2011-2012 } \\
\hline & \multicolumn{2}{|c|}{ Mexican Nationals } & \multicolumn{2}{|c|}{ US Mexicans } & \multicolumn{2}{|c|}{ Mexican Nationals } & \multicolumn{2}{|c|}{ US Mexicans } \\
\hline & $\begin{array}{c}\text { Weighted } \\
\%(\mathrm{SE})\end{array}$ & No. & $\begin{array}{c}\text { Weighted } \\
\% \text { (SE) }\end{array}$ & No. & $\begin{array}{c}\text { Weighted } \\
\% \text { (SE) }\end{array}$ & No. & $\begin{array}{c}\text { Weighted } \\
\% \text { (SE) }\end{array}$ & No. \\
\hline \multicolumn{9}{|l|}{ Men } \\
\hline $\mathrm{N}$ & & 11,735 & & 2,242 & & 11,642 & & 2,785 \\
\hline Age; weighted mean $(\mathrm{SE})^{\mathrm{a}}$ & $35.9(0.2)$ & & $36.1(0.3)$ & & $38.7(0.2)$ & & & \\
\hline \multicolumn{9}{|l|}{ Education } \\
\hline Less than primary & $5.1(0.2)$ & 797 & $11.4(0.8)$ & 264 & $4.3(0.3)$ & 641 & $6.7(0.5)$ & 203 \\
\hline Primary & $62.1(0.7)$ & 7624 & $39.7(1.3)$ & 887 & $59.4(0.7)$ & 7501 & $32.9(1.1)$ & 968 \\
\hline Secondary & $19.3(0.6)$ & 1907 & $42.6(1.3)$ & 952 & $20.5(0.6)$ & 1980 & $51.7(1.2)$ & 1377 \\
\hline College or more & $13.5(0.5)$ & 1407 & $6.4(0.6)$ & 140 & $15.8(0.6)$ & 1520 & $8.7(0.7)$ & 237 \\
\hline Married & $71.6(0.7)$ & 9126 & $70.6(1.2)$ & 1491 & $72.6(0.7)$ & 8874 & $67.5(1.1)$ & 1730 \\
\hline Employed & $86.1(0.5)$ & 10184 & $87.9(0.8)$ & 1930 & $82.7(0.6)$ & 9799 & $81.4(0.9)$ & 2266 \\
\hline \multicolumn{9}{|l|}{ Nativity/duration US Mexicans } \\
\hline Recent immigrant $(<10$ years $)$ & & & $20.9(1.1)$ & 421 & & & $11.0(0.8)$ & 296 \\
\hline Long-term immigrant $(\geq 10$ & & & $37.7(1.2)$ & 830 & & & $46.1(1.2)$ & 1,326 \\
\hline $\begin{array}{l}\text { years) } \\
\text { US-born }\end{array}$ & & & $41.4(1.3)$ & 991 & & & $42.9(1.2)$ & 1,163 \\
\hline \multicolumn{9}{|l|}{ Migration likelihood Mexican } \\
\hline nationals & $43.2(0.7)$ & 4,613 & & & $39.5(0.8)$ & 3,991 & & \\
\hline Low & $28.9(0.7)$ & 3,080 & & & $31.1(0.7)$ & 3,208 & & \\
\hline $\begin{array}{l}\text { Medium } \\
\text { High }\end{array}$ & $27.9(0.6)$ & 4047 & & & $29.4(0.6)$ & 4,443 & & \\
\hline \multicolumn{9}{|l|}{ Smoking status } \\
\hline Current & $37.3(0.7)$ & 4,195 & $24.8(1.1)$ & 603 & $31.7(0.7)$ & 3,390 & $17.8(0.9)$ & 522 \\
\hline Former & $19.8(0.5)$ & 2,595 & $16.2(0.9)$ & 386 & $22.1(0.6)$ & 2,645 & $17.2(0.9)$ & 480 \\
\hline Never & $43.0(0.7)$ & 4,945 & $59.1(1.3)$ & 1253 & $46.2(0.7)$ & 5,607 & $65.0(1.1)$ & 1,783 \\
\hline \multicolumn{9}{|l|}{ Women } \\
\hline $\mathrm{N}$ & & 25,712 & & 2,778 & & 18,099 & & 3,096 \\
\hline Age; weighted mean (SE) & $36.1(0.1)$ & & $36.8(0.3)$ & & $38.6(0.2)$ & & $38.2(0.3)$ & \\
\hline \multicolumn{9}{|l|}{ Education } \\
\hline Less than primary & $8.4(0.2)$ & 2438 & $10.5(0.7)$ & 306 & $5.7(0.2)$ & 1304 & $6.7(0.6)$ & 214 \\
\hline Primary & $65.3(0.5)$ & 17259 & $36.4(1.1)$ & 1084 & $60.8(0.6)$ & 11990 & $31.8(1.0)$ & 1042 \\
\hline Secondary & $19.6(0.4)$ & 4548 & $46.6(1.2)$ & 1211 & $21.2(0.5)$ & 3098 & $51.4(1.1)$ & 1550 \\
\hline College or more & $6.7(0.3)$ & 1467 & $6.4(0.5)$ & 177 & $12.3(0.4)$ & 1707 & $10.0(0.7)$ & 290 \\
\hline Married & $73.4(0.4)$ & 19166 & $70.8(1.0)$ & 1749 & $68.9(0.6)$ & 12721 & $66.1(1.0)$ & 1799 \\
\hline Employed & $24.1(0.4)$ & 6286 & $58.8(1.1)$ & 1615 & $36.0(0.6)$ & 6003 & $58.1(1.1)$ & 1778 \\
\hline
\end{tabular}


Nativity/duration US Mexicans Recent immigrant $(<10$ years $)$

Long-term immigrant $(\geq 10$

years)

US-born

$31.7(1.1) \quad 922$

$9.8(0.7) \quad 314$

$47.7(1.2) \quad 1358$

$46.1(1.1) \quad 1,415$

Migration likelihood Mexican

nationals

Low

$23.5(0.4) \quad 7,164$

$37.5(0.5) \quad 6,468$

$39.1(0.4) \quad 12,080$

High

Smoking status

Current

$11.1(0.3) \quad 2,520$

$6.5(0.2) \quad 1,740$

Former
Never

$82.4(0.4) \quad 21,452$

${ }^{\mathrm{a}}$ Expressed as mean (standard error) 
Table 2. Smoking Status by Migration Status, Mexico and United States, 1999-2012

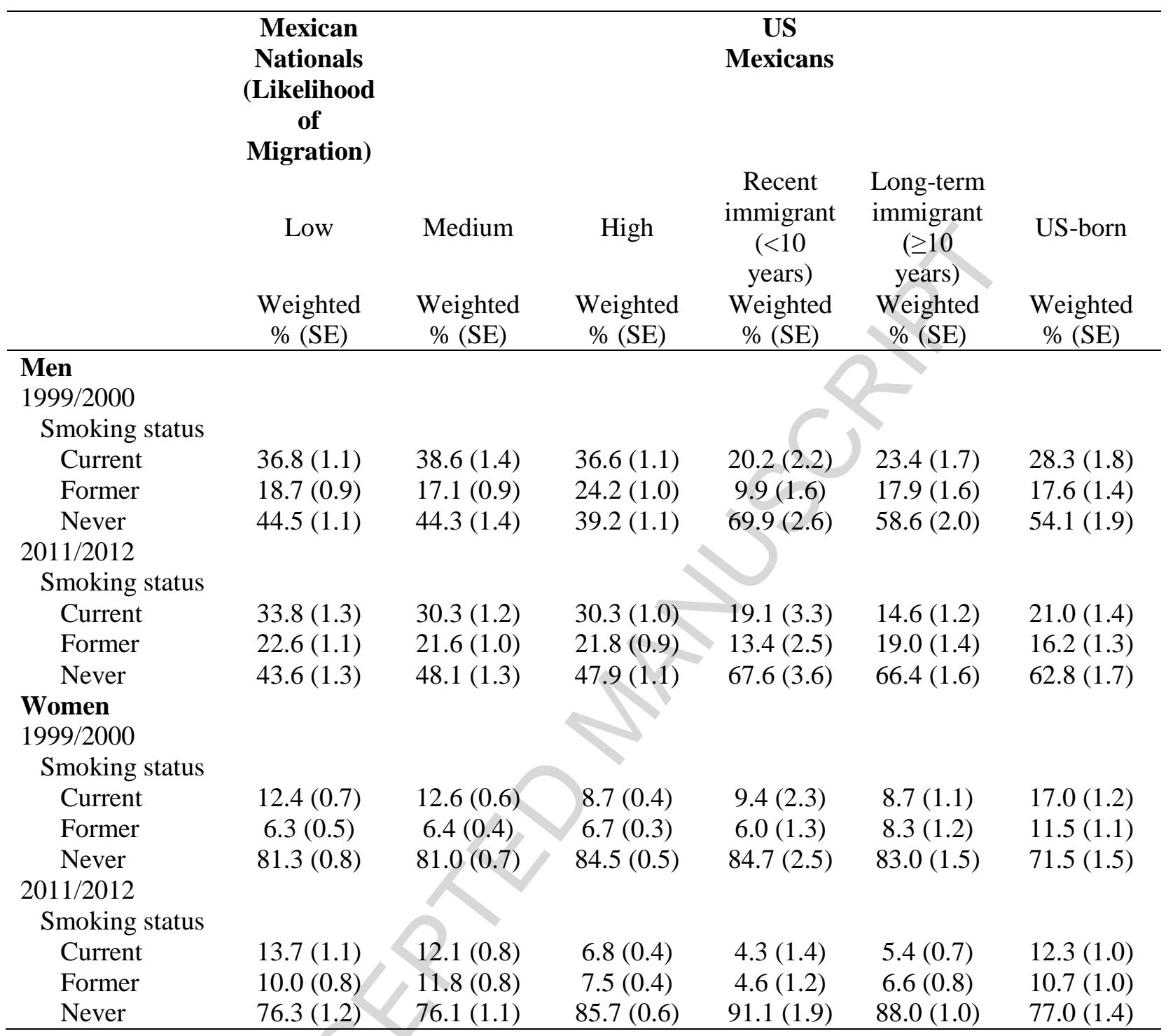


Table 3. Current and Former Compared to Never Smoking Among Men and Women According to Migration Status, Mexico and United States, 1999-2012

\begin{tabular}{|c|c|c|c|c|c|c|c|c|}
\hline & \multicolumn{4}{|c|}{ Men } & \multicolumn{4}{|c|}{ Women } \\
\hline & \multirow{2}{*}{\multicolumn{2}{|c|}{$\begin{array}{l}\text { Current versus } \\
\text { Never Smoking }\end{array}$}} & \multirow{2}{*}{\multicolumn{2}{|c|}{$\begin{array}{l}\text { Former versus } \\
\text { Never Smoking }\end{array}$}} & \multirow{2}{*}{\multicolumn{2}{|c|}{$\begin{array}{l}\text { Current versus Never } \\
\text { Smoking }\end{array}$}} & \multirow{2}{*}{\multicolumn{2}{|c|}{$\begin{array}{l}\text { Former versus } \\
\text { Never Smoking }\end{array}$}} \\
\hline & & & & & & & & \\
\hline & OR & $95 \% \mathrm{CI}$ & OR & $95 \% \mathrm{CI}$ & OR & $95 \% \mathrm{CI}$ & OR & $95 \% \mathrm{CI}$ \\
\hline \multicolumn{9}{|l|}{ Model 1: Adjusted results for $1999 / 2000^{b}$} \\
\hline Mexican nationals-low likelihood & 2.93 & $2.16,3.98$ & 2.30 & $1.58,3.35$ & 1.26 & $0.75,2.11$ & 0.95 & $0.59,1.53$ \\
\hline Mexican nationals-medium likelihood & 2.98 & $2.18,4.08$ & 1.90 & $1.29,2.78$ & 1.35 & $0.80,2.26$ & 1.03 & $0.64,1.63$ \\
\hline Mexican nationals-high likelihood & 3.13 & $2.31,4.24$ & 2.94 & $2.02,4.27$ & 0.90 & $0.54,1.51$ & 0.96 & $0.61,1.52$ \\
\hline Recent immigrants to the US ( $<10$ years) & Referent & & Referent & & Referent & & Referent & \\
\hline Long-term immigrants to the US ( $\geq 10$ years) & 1.32 & $0.93,1.86$ & 1.33 & $0.87,2.04$ & 0.80 & $0.45,1.42$ & 1.05 & $0.61,1.78$ \\
\hline US-born Mexicans & 1.76 & $1.25,2.48$ & 1.53 & $1.00,2.32$ & 1.38 & $0.79,2.40$ & 1.40 & $0.85,2.32$ \\
\hline \multicolumn{9}{|l|}{ Model 2: Adjusted results for $2011 / 2012^{\mathrm{b}}$} \\
\hline Mexican nationals-low likelihood & 2.87 & $1.83,4.49$ & 1.83 & $1.17,2.88$ & 3.65 & $1.79,7.44$ & 2.25 & $1.25,4.03$ \\
\hline Mexican nationals-medium likelihood & 2.33 & $1.49,3.64$ & 1.61 & $1.03,2.52$ & 3.33 & $1.65,6.73$ & 2.74 & $1.54,4.91$ \\
\hline Mexican nationals-high likelihood & 2.19 & $1.42,3.40$ & 1.62 & $1.04,2.52$ & 1.84 & $0.91,3.71$ & 1.69 & $0.95,2.99$ \\
\hline Recent immigrants to the US ( $<10$ years) & Referent & & Referent & & Referent & & Referent & \\
\hline Long-term immigrants to the US ( $\geq 10$ years) & 0.79 & $0.49,1.27$ & 0.97 & $0.61,1.55$ & 1.23 & $0.59,2.58$ & 1.26 & $0.68,2.32$ \\
\hline US-born Mexicans & 1.29 & 2.06 & 1.04 & $0.65,1.68$ & 2.32 & $1.13,4.77$ & 1.94 & $1.06,3.53$ \\
\hline \multicolumn{9}{|l|}{ Model 3: Adjusted results for combined years ${ }^{\mathrm{b}}$} \\
\hline Mexican nationals-low likelihood & 2.93 & $2.24,3.83$ & 2.04 & $1.51,2.76$ & 1.97 & $1.29,3.03$ & 1.45 & $1.00,2.10$ \\
\hline Mexican nationals-medium likelihood & 2.65 & $2.02,3.47$ & 1.76 & $1.30,2.38$ & 1.90 & $1.25,2.90$ & 1.70 & $1.18,2.46$ \\
\hline Mexican nationals-high likelihood & 2.63 & $2.02,3.42$ & 2.14 & $1.59,2.88$ & 1.17 & $0.77,1.77$ & 1.23 & $0.86,1.76$ \\
\hline Recent immigrants to the US ( $<10$ years $)$ & Referent & & Referent & & Referent & & Referent & \\
\hline Long-term immigrants to the US ( $\geq 10$ years) & 0.99 & $0.74,1.32$ & 1.12 & $0.81,1.55$ & 0.84 & $0.53,1.33$ & 0.99 & $0.66,1.48$ \\
\hline US-born Mexicans & 1.50 & $1.12,2.01$ & 1.24 & $0.90,1.72$ & 1.59 & $1.02,2.49$ & 1.53 & $1.04,2.26$ \\
\hline 2012 Wave (Baseline 2000) & 0.76 & $0.70,0.83$ & 0.92 & $0.84,1.01$ & 0.80 & $0.72,0.88$ & 1.19 & $1.07,1.33$ \\
\hline \multicolumn{9}{|l|}{ Model 4: Adjusted results for interaction model ${ }^{\mathrm{b}, \mathrm{c}}$} \\
\hline Mexican nationals-low likelihood for 2000 & 3.01 & $2.22,4.07$ & 2.26 & $1.56,3.29$ & 1.31 & $0.78,2.19$ & 0.95 & $0.59,1.51$ \\
\hline Mexican nationals-medium likelihood for 2000 & 3.02 & $2.22,4.12$ & 1.88 & $1.28,2.75$ & 1.39 & $0.83,2.33$ & 1.04 & $0.66,1.65$ \\
\hline Mexican nationals-high likelihood for 2000 & 3.15 & $2.33,4.27$ & 2.92 & $2.01,4.24$ & 0.96 & $0.57,1.60$ & 1.01 & $0.64,1.58$ \\
\hline Recent immigrants to the US ( $<10$ years) for & Referent & & Referent & & Referent & & Referent & \\
\hline \multicolumn{9}{|l|}{2000} \\
\hline Long-term immigrants to the US ( $\geq 10$ years) for & 1.38 & $0.98,1.94$ & 1.35 & $0.89,2.05$ & 0.84 & $0.48,1.50$ & 1.11 & $0.65,1.88$ \\
\hline
\end{tabular}




\section{0}

US-born Mexicans for 2000

2012 Wave (Baseline 2000, among recent immigrants)

$\begin{array}{llllllll}1.86 & 1.32,2.60 & 1.56 & 1.03,2.35 & 1.42 & 0.83,2.45 & 1.45 & 0.88,2.38 \\ 0.99 & 0.59,1.64 & 1.25 & 0.72,2.18 & 0.38 & 0.16,0.89 & 0.62 & 0.31,1.25 \\ & P<.009 & & P<.005 & & P<.003 & & P<.001\end{array}$

Joint Test of Interaction ( $P$-value)

Abbreviations: CI, confidence interval; OR, odds ratio.

${ }^{a}$ Results from multinomial logistic regression analyses of smoking status according to migration status.

${ }^{\mathrm{b}}$ Adjusted for age, education, employment status, and marital status.

${ }^{\mathrm{c}}$ Interaction model for migrant status and time. 
Figure 1

A)

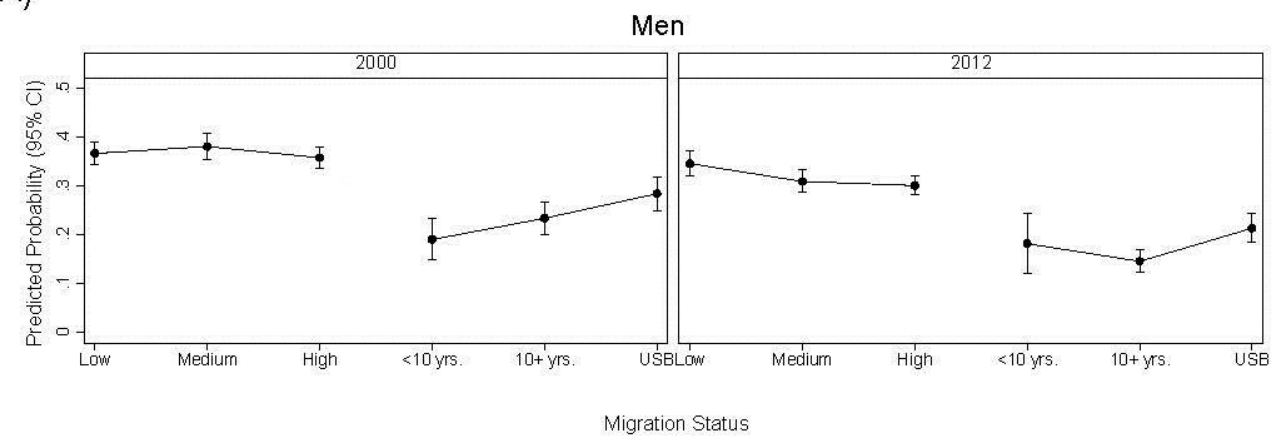

B)

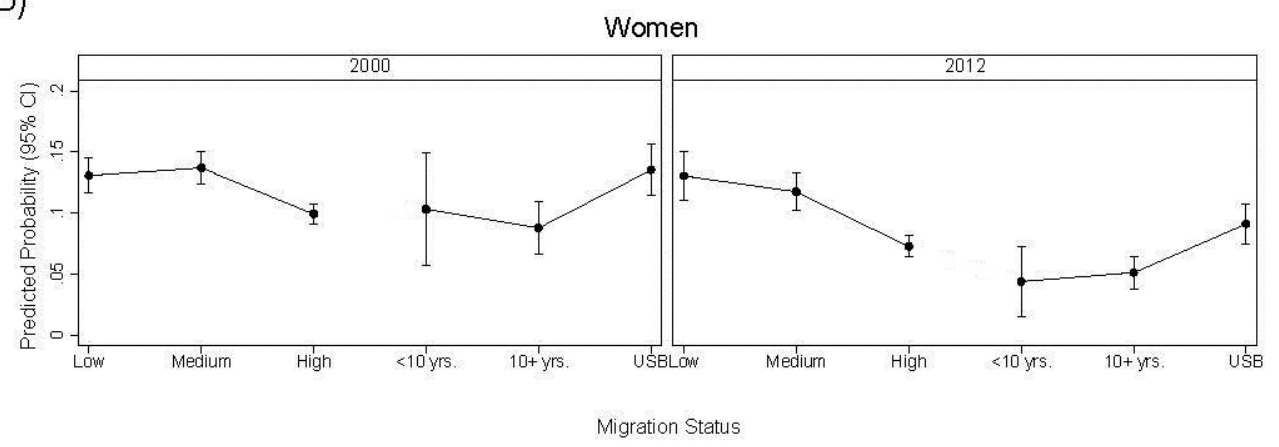


Highlights

- Binational Mexico-US data were used to examine immigrant smoking selectivity.

- Smoking selectivity among Mexican immigrants to the US was apparent.

- Men displayed smoking selectivity in 2000 and 2012.

- Women displayed smoking selectivity in 2012 only.

- Origin country context is important in understanding immigrant smoking. 